\title{
Worksite-based cardiovascular risk screening and management: a feasibility study
}

This article was published in the following Dove Press journal:

Vascular Health and Risk Management

12 June 2017

Number of times this article has been viewed

\section{Raj Padwal' \\ Mohammad Rashead ${ }^{2}$ \\ Jonathan Snider ${ }^{2}$ \\ Louise Morrin ${ }^{2}$ \\ Agnes Lehman ${ }^{2}$ \\ Norm RC Campbell ${ }^{3}$}

'Department of Medicine, Alberta Diabetes Institute and Mazankowski Alberta Heart Institute, University of Alberta, Edmonton, ${ }^{2}$ Cardiovascular Health and Stroke Strategic Clinical Network of Alberta Health Services, ${ }^{3}$ Department of Medicine, Community Health Sciences and Physiology and Pharmacology, O'Brien Institute of Public Health and Libin Cardiovascular Institute of Alberta University of Calgary, Calgary, $A B$, Canada
Correspondence: Raj Padwal Hypertension Clinic, University of Alberta, 5-134A Clinical Sciences Building, II 350 - 83rd Avenue, Edmonton, $A B$ T6G 2G3, Canada

Tel +I 7804923686

Fax +I 7804077277

Email rpadwal@ualberta.ca
Background: Established cardiovascular risk factors are highly prevalent and contribute substantially to cardiovascular morbidity and mortality because they remain uncontrolled in many Canadians. Worksite-based cardiovascular risk factor screening and management represent a largely untapped strategy for optimizing risk factor control.

Methods: In a 2-phase collaborative demonstration project between Alberta Health Services (AHS) and the Alberta Newsprint Company (ANC), ANC employees were offered cardiovascular risk factor screening and management. Screening was performed at the worksite by AHS nurses, who collected baseline history, performed automated blood pressure measurement and pointof-care testing for lipids and A1c, and calculated 10-year Framingham risk. Employees with a Framingham risk score of $\geq 10 \%$ and uncontrolled blood pressure, dyslipidemia, or smoking were offered 6 months of pharmacist case management to optimize their risk factor control.

Results: In total, 87 of 190 (46\%) employees volunteered to undergo cardiovascular risk factor screening. Mean age was $44.5 \pm 11.9$ years, 73 (83.9\%) were male, $14(16.1 \%)$ had hypertension, $4(4.6 \%)$ had diabetes, $12(13.8 \%)$ were current smokers, and $9(10 \%)$ had dyslipidemia. Of 36 employees with an estimated Framingham risk score of $\geq 10 \%, 21(58 \%)$ agreed to receive case management and $15(42 \%)$ attended baseline and 6-month follow-up case management visits. Statistically significant reductions in left arm systolic blood pressure $(-8.0 \pm 12.4 \mathrm{mmHg}$; $p=0.03$ ) and triglyceride levels $(-0.8 \pm 1.4 \mathrm{mmol} / \mathrm{L} ; p=0.04)$ occurred following case management Conclusion: These findings demonstrate the feasibility and usefulness of collaborative, worksite-based cardiovascular risk factor screening and management. Expansion of this type of partnership in a cost-effective manner is warranted.

Keywords: blood pressure, dyslipidemia, smoking, pharmacist, worksite

\section{Background}

Cardiovascular disease, which includes heart disease and stroke, is the second leading cause of mortality in Canada, accounting for 125,000 deaths or $35 \%$ of all fatalities in $2013 .{ }^{1}$ The 4 most important modifiable risk factors for cardiovascular disease are hypertension, dyslipidemia, diabetes, and smoking. ${ }^{2,3}$ These risk factors are highly prevalent in Canadians - 23\% have hypertension, $45 \%$ have dyslipidemia, $9 \%$ have diabetes, and $18 \%$ smoke. ${ }^{4-6}$

Despite the widespread availability of proven efficacious treatments, cardiovascular risk factor control rates are unacceptably low. For example, 37\% of Canadians with hypertension and $81 \%$ of Canadians with dyslipidemia are not controlled to target levels. ${ }^{4,7}$ These care-gaps reflect a lost opportunity to improve health, prevent premature death and disability, and reduce unnecessary health care expenditures. 
As traditional methods of controlling cardiovascular risk factors (largely consisting of patients seeing their health care provider to get screened and treated) have not fully optimized risk factor control, additional approaches are needed. Given that Canadian workers spend an average of 30 hours per week at work, worksite cardiovascular risk screening and management programs represent a promising option to improve risk factor detection and control in working-aged Canadians. ${ }^{8}$ In a recently performed cross-sectional survey of Canadian workers, $40 \%$ were unaware of having at least one uncontrolled cardiovascular risk factor. ${ }^{9}$ Further, individuals with uncontrolled risk were less likely than those with no risk factors to engage in healthy behaviors. ${ }^{9}$ This underscores the importance of identifying unrecognized risk in order that it can be appropriately managed.

The purpose of this report is to detail the results of a worksite-based collaboration between Alberta Health Services (AHS) and the Alberta Newsprint Company (ANC). The primary objective of this demonstration project was to examine the feasibility and usefulness of using embedded health care providers to perform cardiovascular risk factor screening and management onsite in the workplace.

\section{Methods}

Prior to study initiation, approval from University of Alberta research ethics board was obtained. Informed consent was obtained from all participants.

\section{Setting}

This worksite-based program was part of a larger, multipronged AHS initiative, termed the Vascular Risk Reduction Initiative, aimed at optimizing the screening and control of cardiovascular risk factors in Albertans by using novel means of health care service delivery. ANC is a newsprint producer based in Whitecourt, AB (estimated 2016 population of approximately 10,000). At the time this project was conducted, the company had 190 employees. AHS is Canada's largest fully integrated health services provider, responsible for delivering care to the $>4$ million residents of the province of Alberta.

\section{Screening}

Cardiovascular risk factor screening was offered to all ANC employees. Two AHS nurses performed screening procedures onsite at the company pulp mill over a 5-week period. Screening took approximately 30 minutes per worker and consisted of collecting data on baseline demographics, history of cardiovascular risk factors or disease, family history, weight, height, body mass index (BMI), blood pressure, and point-of-care
A1c and lipids. Weight was measured to the nearest tenth of a kilogram with the subject wearing light clothing and no shoes. Blood pressure was measured using the previously validated Watch BP Office (Microlife, Taipei, Taiwan) automated device in both arms simultaneously using recommended techniques. ${ }^{10,11}$ The first reading was discarded, and the mean of the latter 2 readings was calculated. DCA Vantage Analyzer (Siemens, Munich, Germany) and Cholestech LDX Analyzer (Alere, Waltham, MA, USA) devices were used to obtain A1c and lipid measurements. Ten-year cardiovascular disease risk and vascular age were estimated using the Canadian Cardiovascular Society Framingham Risk Score Calculator.

Hypertension was defined according to past history, use of medications, and/or a blood pressure $\geq 140 / 90 \mathrm{mmHg}$ ( $\geq 130 / 80$ in participants with diabetes). Dyslipidemia was defined according to past history, use of medications, and/or a high low-density lipoprotein (LDL) cholesterol level (defined as $\geq 5.0 \mathrm{mmol} / \mathrm{L}$ in subjects with a Framingham risk estimate of $<10 \%, \geq 3.5 \mathrm{mmol} / \mathrm{L}$ for a risk estimate of $10-19 \%$, and $\geq 2.0 \mathrm{mmol} / \mathrm{L}$ for a risk estimate of $\geq 20 \%$ ). Diabetes was defined according to self-report, medication use, and/or an A1c $\geq 6.5 \%$. Smoking was defined according to self-report.

\section{Case management}

Workers with uncontrolled blood pressure, LDL cholesterol, and/or smoking status, and a calculated Framingham risk score $\geq 10 \%$ were offered case management to optimize their cardiovascular risk profiles over a 6-month time frame. Two local pharmacists with full prescribing privileges, as per pharmacists' scope of practice in Alberta, performed case management. The case managers primarily focused on addressing uncontrolled blood pressure, dyslipidemia, and smoking. Management was based on contemporary guidelines and consisted of health behavior counseling and appropriate pharmacotherapy. ${ }^{10}$ Health behavior counseling followed the recommendations of the Canadian Hypertension Guidelines and included recommendations to reduce sodium intake towards $2 \mathrm{~g} /$ day, achievement/maintenance of a normal body weight $\left(18.5-24.9 \mathrm{~kg} / \mathrm{m}^{2}\right)$, increase aerobic physical activity to 30-60 minutes per day on 4-7 days per week, and consumption of the Dietary Approaches to Stop Hypertension diet. ${ }^{10}$ Risk factor targets were as follows:

1. Blood pressure $<140 / 90 \mathrm{mmHg}(130 / 80 \mathrm{mmHg}$ for those with diabetes)

2. An LDL cholesterol level of $<2.0 \mathrm{mmol} / \mathrm{L}$ or a $50 \%$ decline

3. Nonsmoking status 
Secondary outcomes included changes in A1c levels, body weight, BMI, and the 10-year total Framingham cardiovascular risk estimate. Changes in prescription medications were not tracked.

\section{Analyses}

Descriptive analyses were first performed, including calculation of means, standard deviations, and proportions. Changes in cardiovascular risk factors from baseline to follow-up were analyzed using paired Student's $t$-tests for continuous variables and McNemar tests for dichotomous ones. $p$-Values $<0.05$ were considered statistically significant. Analyses were conducted using Excel (Microsoft, Redmond, WA, USA).

\section{Results}

In total, 87 workers received cardiovascular risk factor screening. Baseline characteristics of the study population, stratified by receipt of case management, are summarized in Table 1 . Mean age was $44.5 \pm 11.9$ years, 73 (83.9\%) were male, 14 (16.1\%) had hypertension, 4 (4.6\%) had diabetes, $12(13.8 \%)$ were current smokers, and $9(10 \%)$ had dyslipidemia. Casemanaged workers were older, more likely male, and had a greater cardiovascular risk factor burden.

Thirty-six (41\%) workers had an estimated Framingham risk score of $\geq 10 \%$ and were smokers or had uncontrolled blood pressure or lipids. Of these, 21 (58\%) agreed to receive case management. These individuals had a mean 10-year

Table I Baseline characteristics

\begin{tabular}{|c|c|c|c|}
\hline Variables & Total population $(\mathrm{N}=87)$ & Non-case managed $(n=65)$ & Case managed $(n=2 I)$ \\
\hline Age (years), mean $\pm S D$ & $44.5 \pm 11.9$ & $42 \pm 12.3$ & $51.6 \pm 7.4$ \\
\hline Male, n (\%) & $73(83.9)$ & $14(100)$ & $0(0)$ \\
\hline \multicolumn{4}{|l|}{ Ethnicity } \\
\hline Caucasian, n (\%) & $77(90.6)$ & $54(87.1)$ & $23(100)$ \\
\hline Asian, $\mathrm{n}(\%)$ & $4(4.7)$ & $4(6.5)$ & $0(0)$ \\
\hline Other, n (\%) & $4(4.7)$ & $4(6.5)$ & $0(0)$ \\
\hline Hypertension, n (\%) & $14(16.1)$ & $10(15.6)$ & $4(17.4)$ \\
\hline Type 2 diabetes, $\mathrm{n}(\%)$ & $4(4.6)$ & $\mathrm{I}(\mathrm{I} .6)$ & $3(13.0)$ \\
\hline Dyslipidemia, n (\%) & $9(10.3)$ & $5(7.8)$ & $4(17.4)$ \\
\hline Coronary artery disease, $n(\%)$ & $2(2.3)$ & $2(3.1)$ & $0(0)$ \\
\hline Coronary angioplasty, $\mathrm{n}(\%)$ & $\mathrm{I}(\mathrm{I} .2)$ & $\mathrm{I}(\mathrm{I} .6)$ & $0(0)$ \\
\hline Coronary bypass, n (\%) & $2(2.3)$ & $2(3.1)$ & $0(0)$ \\
\hline \multicolumn{4}{|l|}{ Smoker, n (\%) } \\
\hline Current & $12(13.8)$ & $7(10.9)$ & $5(21.7)$ \\
\hline Past & $21(27.6)$ & $18(31.6)$ & $3(15.8)$ \\
\hline \multicolumn{4}{|l|}{ Systolic BP (mmHg), mean \pm SD } \\
\hline Left arm & $135.2 \pm 12.6$ & $132.8 \pm \mid 2.1$ & $141.8 \pm 1 \mid .7$ \\
\hline Right arm & $137.0 \pm 12.7$ & $134.1 \pm 12.0$ & $|44.7 \pm| \mid .3$ \\
\hline \multicolumn{4}{|l|}{ Diastolic BP $(\mathrm{mmHg})$, mean \pm SD } \\
\hline Left arm & $85.8 \pm 8.6$ & $84.1 \pm 8.3$ & $90.7 \pm 7.6$ \\
\hline Right arm & $86.5 \pm 9.8$ & $84.2 \pm 8.9$ & $92.7 \pm 9.7$ \\
\hline Heart rate (beats/min), mean $\pm S D$ & $71.3 \pm 12$ & $69.4 \pm 11.6$ & $76.5 \pm 11.8$ \\
\hline Weight $(\mathrm{kg})$, mean \pm SD & $90.3 \pm 16.5$ & $88.0 \pm 15.9$ & $96.6 \pm 16.6$ \\
\hline BMI $\left(\mathrm{kg} / \mathrm{m}^{2}\right)$, mean $\pm \mathrm{SD}$ & $29.1 \pm 4.0$ & $28.7 \pm 3.8$ & $30.3 \pm 4.5$ \\
\hline $\begin{array}{l}\text { Total cholesterol }(\mathrm{mmol} / \mathrm{L}) \\
\text { mean } \pm \mathrm{SD}\end{array}$ & $4.9 \pm 1.1$ & $4.8 \pm 1.2$ & $5.1 \pm 1.1$ \\
\hline $\begin{array}{l}\mathrm{HDL} \text { cholesterol }(\mathrm{mmol} / \mathrm{L}) \\
\text { mean } \pm \mathrm{SD}\end{array}$ & $1.2 \pm 0.4$ & $1.2 \pm 0.5$ & $1.1 \pm 0.2$ \\
\hline $\begin{array}{l}\text { LDL cholesterol }(\mathrm{mmol} / \mathrm{L}) \\
\text { mean } \pm \mathrm{SD}\end{array}$ & $2.7 \pm 0.9$ & $2.7 \pm 0.9$ & $2.9 \pm 0.9$ \\
\hline Triglycerides $(\mathrm{mmol} / \mathrm{L})$, mean $\pm \mathrm{SD}$ & $2.0 \pm 1.5$ & $1.8 \pm 1.4$ & $2.8 \pm 1.7$ \\
\hline \multicolumn{4}{|l|}{ 10-year Framingham risk estimate } \\
\hline Total mean \pm SD & $12.6 \pm 11.4$ & $9.0 \pm 9.1$ & $22.8 \pm 11.2$ \\
\hline High risk, n (\%) & $21(24.1)$ & $9(14.1)$ & $12(52.2)$ \\
\hline Moderate risk, $\mathrm{n}(\%)$ & $15(17.2)$ & $4(6.3)$ & II (47.8) \\
\hline Low risk, n (\%) & $51(58.6)$ & $51(79.7)$ & $0(0)$ \\
\hline Vascular age, mean \pm SD & $52.7 \pm 15.3$ & $48.0 \pm 14.0$ & $65.8 \pm 10.6$ \\
\hline Alc, mean $\pm S D$ & $5.4 \pm 0.7$ & $5.2 \pm 0.3$ & $5.8 \pm 1.2$ \\
\hline
\end{tabular}

Abbreviations: SD, standard deviation; BP, blood pressure; BMI, body mass index; HDL, high-density lipoprotein; LDL, low-density lipoprotein. 
Framingham risk score of $22.8 \%$. Fifteen (42\%) attended baseline and 6-month follow-up case management visits and, in these individuals, statistically significant reductions in left arm systolic blood pressure $(-8.0 \pm 12.4 \mathrm{mmHg} ; p=0.03)$ and triglyceride $(-0.8 \pm 1.4 \mathrm{mmHg} ; p=0.04)$ levels occurred after case management (Table 2). Of 5 smokers who agreed to case management, 4 did not complete case management and the remaining one quit smoking following case management. No substantial changes in BMI, A1c, or Framingham risk score were observed.

\section{Discussion}

In summary, the results of this pilot project confirm that worksite-based cardiovascular risk factor screening and management is both feasible and useful. In the screening phase of the program, $>40 \%$ of the workers receiving screened were identified as having a moderate-to-high cardiovascular risk level. In the workers who received case management, improvements in cardiovascular risk factors, particularly blood pressure and triglycerides, were demonstrated.

The most novel aspect of this collaborative project is that it involved embedding AHS and community clinicians within the worksite to deliver care. This approach moves beyond the traditional "worksite wellness" program model that focuses on educational interventions alone. Traditional approaches have unsurprisingly had limited effectiveness because they do not involve use of the most effective and proven aspects of cardiovascular risk factor control, prescription of antihypertensive drugs and statins. ${ }^{12-14}$ Embedding clinicians in the worksite greatly increases convenience for workers and also obviates the need for them to take time off to attend clinic appointments. Indeed, this type of care model has the potential to reach Canadians who do not typically seek medical care and who are less likely to be aware of having uncontrolled cardiovascular risk, such as younger individuals and males. ${ }^{15}$

Despite encouragement, only 15 subjects, or $42 \%$ of the high-risk patients, followed through with case management. This reflects known practical realities in engaging high-risk patients in their care and is highly likely to be found with replication of this project.

\section{Limitations}

The major limitations of this study are the relatively small sample size, lack of controls, and short duration of follow-up. The lack of a control group precludes adjustment for temporal trends. In addition, an economic assessment was not performed to evaluate the cost-effectiveness of this strategy. These limitations indicate the need to confirm the robustness of these results in larger sample sizes and over more sustained follow-up periods.

\section{Conclusion}

The results of this study verify the worksite-based cardiovascular risk factor screening and management is a viable strategy for identifying and reducing latent cardiovascular

Table 2 Changes in cardiovascular risk factors and profile following case management

\begin{tabular}{|c|c|c|c|}
\hline Variables & Baseline $(n=15)$ & Follow-up $(n=15)$ & Difference ( $p$-value) \\
\hline \multicolumn{4}{|l|}{ Systolic BP (mmHg), mean \pm SD } \\
\hline Left arm & $|4| .4 \pm 12.3$ & $133.4 \pm 1 \mid .7$ & $-8.0 \pm 12.4(0.03)$ \\
\hline Right arm & $143.8 \pm 12.4$ & $136.0 \pm 12.8$ & $-7.8 \pm 15 . \mid(0.07)$ \\
\hline \multicolumn{4}{|l|}{ Diastolic BP $(\mathrm{mmHg})$, mean $\pm \mathrm{SD}$} \\
\hline Left arm & $89.6 \pm 6.6$ & $88.7 \pm 9.3$ & $-0.9 \pm 9.1(0.70)$ \\
\hline Right arm & $92.6 \pm 10.2$ & $89.5 \pm 9.6$ & $-3.1 \pm 10.3(0.26)$ \\
\hline Controlled blood pressure, $\mathrm{n}(\%)$ & $3(20)$ & $5(33)$ & $2(13)(0.61)$ \\
\hline Heart rate (beats/min), mean $\pm S D$ & $74.8 \pm 12.0$ & $74.3 \pm 11.7$ & $-0.5 \pm I 1.8(0.86)$ \\
\hline BMI $\left(\mathrm{kg} / \mathrm{m}^{2}\right)$, mean $\pm \mathrm{SD}$ & $30.1 \pm 4.2$ & $29.9 \pm 5.2$ & $-0.2 \pm 1.44(0.65)$ \\
\hline Smoker, n (\%) & I (6.7) & $0(0.0)$ & $-I(6.7)(n / a)$ \\
\hline Total cholesterol $(\mathrm{mmol} / \mathrm{L})$, mean $\pm \mathrm{SD}$ & $5.0 \pm 0.8$ & $4.8 \pm 1.0$ & $-0.2 \pm 0.82(0.37)$ \\
\hline $\mathrm{HDL}$ cholesterol (mmol/L), mean $\pm \mathrm{SD}$ & $1.1 \pm 0.3$ & $1.1 \pm 0.2$ & $-0.0 \pm 0.18(0.87)$ \\
\hline LDL cholesterol (mmol/L), mean \pm SD & $2.9 \pm 0.9$ & $2.7 \pm 1.0$ & $0.2 \pm 1.0(0.91)$ \\
\hline Triglycerides (mmol/L), mean \pm SD & $2.8 \pm 1.5$ & $2.0 \pm 1.0$ & $-0.8 \pm 1.4(0.04)$ \\
\hline Controlled dyslipidemia, n (\%) & $6(40)$ & $6(40)$ & $0(0)(0.47)$ \\
\hline \multicolumn{4}{|l|}{ 10-year Framingham risk estimate } \\
\hline Total, mean \pm SD & $21.6 \pm 8.3$ & $20.6 \pm 8.1$ & $-1.0 \pm 0.1(0.70)$ \\
\hline Vascular age, mean $\pm S D$ & $65.1 \pm 9.1$ & $64.1 \pm 10.7$ & $-0.9 \pm 5.52(0.52)$ \\
\hline Alc, mean \pm SD & $5.8 \pm 1.4$ & $5.1 \pm 1.8$ & $-0.7 \pm 0.02(0.11)$ \\
\hline
\end{tabular}

Abbreviations: BP, blood pressure; SD, standard deviation; BMI, body mass index; n/a, not available; HDL, high-density lipoprotein; LDL, low-density lipoprotein. 
risk. These findings demonstrate how health service providers and employers can collaborate to improve the health of workers. Future work should focus on expanding this pilot project in a cost-effective manner.

\section{Acknowledgments}

The authors would like to acknowledge the contributions of the staff and workers of the ANC and the community pharmacists who participated in this project. This study was funded by AHS.

\section{Disclosure}

The authors report no conflicts of interest in this work.

\section{References}

1. Statistics Canada. Leading causes of death, by sex. 2013. Available from: http://www.statcan.gc.ca/tables-tableaux/sum-som/101/cst01/ hlth36a-eng.htm. Accessed March 17, 2017.

2. O’Donnell MJ, Xavier D, Liu L, et al; INTERSTROKE Investigators. Risk factors for ischaemic and intracerebral haemorrhagic stroke in 22 countries (the INTERSTROKE study): a case-control study. Lancet. 2010;376(9735):112-123.

3. Yusuf S, Hawken S, Ounpuu S, et al; INTERHEART Study Investigators. Effect of potentially modifiable risk factors associated with myocardial infarction in 52 countries (the INTERHEART study): case-control study. Lancet. 2004;364(9438):937-952.

4. Padwal RS, Bienek A, McAlister FA, Campbell NR; Outcomes Research Task Force of the Canadian Hypertension Education Program. Epidemiology of hypertension in Canada: an update. Can J Cardiol. 2016;32(5): 687-694.

5. Shields M, Carroll MD, Ogden CL. Adult obesity prevalence in Canada and the United States. NCHS Data Brief. 2011;56:1-8.
6. Statistics Canada. Diabetes statistics in Canada. 2017. Available from: http://www.diabetes.ca/how-you-can-help/advocate/why-federalleadership-is-essential/diabetes-statistics-in-canada. Accessed March 17, 2017.

7. Joffres M, Shields M, Tremblay MS, Connor Gorber S. Dyslipidemia prevalence, treatment, control, and awareness in the Canadian Health Measures Survey. Can J Public Health. 2013;104(3):e252-e257.

8. Statistics Canada. Weekly hours of hourly paid employees. 2016. Available from: http://www.statcan.gc.ca/tables-tableaux/sum-som/101/cst01/ labr82-eng.htm. Accessed March 17, 2017.

9. Jacobs JC, Burke S, Rouse M, Sarma S, Zaric G. Cardiovascular disease risk awareness and its association with preventive health behaviors: evidence from a sample of Canadian workplaces. J Occup Environ Med. 2016;58(5):459-465.

10. Leung AA, Nerenberg K, Daskalopoulou SS, et al; CHEP Guidelines Task Force. Hypertension Canada's 2016 Canadian Hypertension Education Program guidelines for blood pressure measurement, diagnosis, assessment of risk, prevention and treatment of hypertension. Can J Cardiol. 2016;32(5):569-588.

11. Stergiou GS, Tzamouranis D, Protogerou A, Nasothimiou E, Kapralos C. Validation of the Microlife Watch BP Office professional device for office blood pressure measurement according to the International Protocol. Blood Press Monit. 2008;13(5):299-303.

12. Anderson LM, Quinn TA, Glanz K, et al; Task Force on Community Preventive Services. The effectiveness of worksite nutrition and physical activity interventions for controlling employee overweight and obesity: a systematic review. Am J Prev Med. 2009;37(4):340-357.

13. Cholesterol Treatment Trialists' (CTT) Collaboration. Efficacy and safety of more intensive lowering of LDL cholesterol: a meta-analysis of data from 170,000 participants in 26 randomised trials. Lancet. 2010;376(9753):1670-1681.

14. Turnbull F; Blood Pressure Lowering Treatment Trialists' Collaboration. Effects of different blood-pressure-lowering regimens on major cardiovascular events: results of prospectively designed overviews of randomised trials. Lancet. 2003;362(9395):1527-1535.

15. Gee ME, Bienek A, McAlister FA, et al. Factors associated with lack of awareness and uncontrolled high blood pressure among Canadian adults with hypertension. Can J Cardiol. 2012;28(3):375-382.
Vascular Health and Risk Management

\section{Publish your work in this journal}

Vascular Health and Risk Management is an international, peerreviewed journal of therapeutics and risk management, focusing on concise rapid reporting of clinical studies on the processes involved in the maintenance of vascular health; the monitoring, prevention and treatment of vascular disease and its sequelae; and the involvement of

\section{Dovepress}

metabolic disorders, particularly diabetes. This journal is indexed on PubMed Central and MedLine. The manuscript management system is completely online and includes a very quick and fair peer-review system, which is all easy to use. Visit http://www.dovepress.com/ testimonials.php to read real quotes from published authors. 